\title{
TRADIÇÃO E INOVAÇÃO NA ERA DIGITAL: VALOR SIMBÓLICO, CULTURA E MARKETING ${ }^{1}$
}

\author{
Cecília Oliveira Bezerra ${ }^{2}$
}

Eduardo Paes Barreto Davel ${ }^{3}$

http://dx.doi.org/10.1590/1413-2311.169.63214

\section{RESUMO}

O objetivo deste caso de ensino é gerar aprendizagem sobre a criação de valor simbólico e cultural de bens de consumo no contexto da comunicação virtual. Dessa forma, o caso também permite aprender sobre a importância desse tipo de valor dentro das práticas de marketing digital. A história gravita em torno da gestora Anna, que enfrenta uma crise na empresa que administra com sua mãe, diretora e fundadora. A Tear é uma empresa no segmento de moda, que confecciona objetos caracterizados pelo design sofisticado, trabalho artesanal refinado e peças únicas. Ao atender uma consumidora que pretende adquirir um vestido de noiva, Anna escuta um relato sobre a Tiffany's \& Co. e vislumbra, então, uma alternativa potencial para enfrentar a crise. Depois de conversar com a diretora, decide investir em uma visita na sede da Tiffany's \& Co. em Nova Iorque, nos Estudos Unidos. Ela conversa com várias pessoas e adquire várias experiências. Com tudo isso, Anna descobre como o marketing digital e o comércio eletrônico podem transformar produtos artesanais em objetos de desejo, conciliando inovação com tradição. Todavia, descobre também o inverso: como a dimensão cultural e simbólica pode qualificar as práticas de marketing digital.

Palavras-chave: Marketing Digital. Valor Simbólico. Artesanato. Produto Cultural. Tiffany's \& Co.

\section{TRADITION AND INNOVATION IN THE DIGITAL ERA: SYMBOLIC VALUE, CULTURE AND MARKETING}

\begin{abstract}
The aim of this teaching case is to generate learning about the creation of symbolic and cultural value of goods in the context of virtual communication. Thus, the case also lets us learn about the importance of this kind of value within the digital marketing practices. The story takes place around the management of Anna, facing a crisis in the company that she manages with his mother, current director and founder. Tear is a company in the fashion segment, which manufactures objects characterized by sophisticated design, refined
\end{abstract}

\footnotetext{
${ }^{1}$ Recebido em 22/03/2016; aprovado em 20/07/2017.

${ }^{2}$ Instituto Federal da Bahia - ceciliabezerra@uol.com.br.

${ }^{3}$ Universidade Federal da Bahia - davel.eduardo@gmail.com.
} 
craftsmanship and unique pieces. When Anna was helping a costumer choosing a wedding dress, hears a story about Tiffany's \& Co. and perceive it as a potential alternative to face the company crisis. After talking to the director, Anna decides to visit the headquarters of Tiffany \& Co. in New York. She talks to several people and had different experiences. In the end, Anna discovers how digital marketing and e-commerce can transform craft products into objects of desire, combining innovation with tradition. However, she also gets the opposite: how cultural and symbolic dimension can qualify digital marketing practices.

Keywords: Digital Marketing. Symbolic Value. Crafts. Cultural Product. Tiffany’s \& Co.

\section{TRADICIÓN E INNOVACIÓN EN LA ERA DIGITAL: VALOR SIMBÓLICO, CULTURA Y MARKETING}

\section{RESUMEN}

El objetivo de este caso de enseñanza es generar aprendizaje sobre la creación de valor simbólico y cultural de los bienes en el contexto de la comunicación virtual. Por lo tanto, el caso también nos permite aprender sobre la importancia de este tipo de valor dentro de las prácticas de marketing digital. La historia tiene lugar en torno a la gestión de Anna, frente a una crisis en la empresa que maneja con su madre, actual directora y fundadora. Tear es una empresa del segmento de la moda que fabrica objetos caracterizados por un diseño sofisticado, artesanía refinada y piezas únicas. Cuando Anna estaba ayudando a un cliente a elegir un vestido de novia, escucha una historia sobre Tiffany's \& Co. y ella percibe como una alternativa potencial para enfrentar la crisis de la compañía. Después de hablar con el director, Anna decide visitar la sede de Tiffany \& Co. en Nueva York. Ella habla con varias personas y tuvo diferentes experiencias. Al final, Anna descubre cómo el marketing digital y el comercio electrónico pueden transformar los productos artesanales en objetos de deseo, combinando la innovación con la tradición. Sin embargo, también se percibe lo opuesto: cómo la dimensión cultural y simbólica puede calificar las prácticas de marketing digital.

Palabras-clave: Marketing Digital. Valor Simbólico. Artesanía. Producto Cultural. Tiffany's \& Co.

\section{CASO DE ENSINO: TEAR CRIANDO VALOR NA ERA DIGITAL}

\subsection{A CRISE NA TEAR ${ }^{4}$}

Lá estava Anna, conversando com sua mãe sobre a situação financeira da TEAR. Enquanto Anna ouvia as queixas e orientações pensava sobre os desafios que viriam pela frente. Quando a TEAR deixou de ser aquela loja em que ela cresceu?

\footnotetext{
${ }^{4}$ Apesar da empresa TEAR e sua gestora serem fictícias, são baseadas na prática real de organizações do setor da moda e do design na Bahia. As informações sobre a Tiffany's e outras organizações de Nova Iorque são verídicas; foram coletadas por meio de entrevistas semiestruturadas, observação direta e análise de documentos.
} 
Nina, mãe de Anna, dirigia a TEAR há quase 30 anos. A TEAR era uma empresa de moda que começou de maneira informal e acabou tornando-se uma rede de quatro lojas distribuídas em três capitais do Nordeste Brasileiro.

Desde sua fundação, Nina tinha priorizado produtos que carregassem aspectos do design contemporâneo e da sofisticação do artesanato baiano, principalmente o das rendas. A TEAR comercializava de vestidos de noivas até peças mais clássicas do vestuário feminino.

Apesar do primor pela delicadeza e elegância, a loja não era muito sofisticada. Na verdade, quem olhasse de fora, não conseguia perceber a riqueza que estava dentro daquelas araras. Talvez por Nina ser uma pessoa discreta, a TEAR nunca se preocupou muito com o design de interiores das lojas. Quando Anna questionava sobre a disposição das lojas e dos produtos, Nina costumava dizer que confiava no boca a boca que suas clientes faziam.

$\mathrm{Na}$ escolha dos outros pontos de venda também foi assim. Nina procurava um local bonito, quando possível dentro de algum shopping da cidade, estruturava a loja com araras e cabides e dispunha seus produtos de forma elegante, mas discreta. Por muitos anos, essa foi a forma de gestão da TEAR, extremamente intuitiva e discreta. A única coisa que Nina nunca abriu mão foi de vender produtos que carregassem as tradições da Bahia.

Anna era uma mulher de 28 anos, administradora de formação com cursos na área de administração, moda e design. Colecionava experiência em empresas bem-sucedidas do vestuário feminino. A TEAR era a segunda casa de Anna, praticamente crescera ali. No dia a dia, Anna era uma viciada em tecnologia, típica usuária das plataformas e redes digitais que pudessem facilitar a sua vida, até a amorosa.

Sua rotina incluía o uso diário da sua Agenda Google para organizar seus compromissos, um Aplicativo para organizar suas finanças. Usava, também, aplicativos como o Zoom e o Buscapé para comparação dos preços do seus eletrodomésticos e equipamentos eletrônicos, três de supermercados diferentes da sua cidade para organizar as compras mês, além do fato de que Anna também estava fazendo uma reciclagem do seu inglês em um curso à distância. Tinha ainda perfil em mais de seis redes sociais diferentes e duas redes de relacionamento: Tinder e Hppn. Pois é, Anna era uma amante da tecnologia.

Apesar de ter trabalhado em outras empresas do segmento, tinha optado em não se envolver com a TEAR, pois em uma breve experiência de verão, entrou em conflito com sua mãe quando disse que não concordava com a forma como os produtos eram expostos, bem como as estratégias de precificação.

No entanto, dessa vez era diferente. A TEAR estava seguindo para o fechamento da segunda loja. Com a entrada dos tecidos chineses no mercado brasileiro, sua mãe tinha 
reduzido demasiadamente a margem dos seus produtos. Como a garantia de um pagamento justo a todas as rendeiras, crocheteiras e costureiras era um dos pilares fundamentais da loja, Nina passou a acreditar que ganhar menos era a única forma de manter os negócios em dia. Ao contrário do que esperava, as contas não estavam mais fechando e Nina, após 30 anos de administração, não sabia o que fazer para salvar o seu negócio.

As duas param para conversar sobre a questão. Xícaras de café na mão, sequilhos na mesa e Anna ouvindo, cuidadosamente, sua mãe contar todas as tentativas fracassadas para melhorar a condição da TEAR. Nesse momento, Anna interrompeu sua mãe:

- Mãe, faremos assim, vou passar uma semana visitando as lojas, em seguida, pretendo pesquisar um pouco e, por fim, te proponho um projeto de enfrentamento da crise. Se você achar que é viável, colocamos em prática. O que lhe parece?

\subsection{TIFFANY'S \& CO. E NOVA IORQUE: CAMINHOS PARA NOVAS IDEIAS E PRÁTICAS?}

Anna começou sua experiência de observação visitando algumas filiais. As três lojas que ficavam fora da cidade eram situadas em regiões de comércio intenso, dentro de grandes shoppings. Cada loja tinha uma fachada diferente, apesar da uniformidade das cores, terra, branco e dourado. Tudo muito elegante e de bom gosto, mas sem muita padronização na forma de decoração e na disposição dos produtos.

Quando Anna retornou a matriz, quis acompanhar o atendimento às clientes. Ela ainda estava confusa com algumas informações. Se por um lado a TEAR estava passando por uma crise, por outro ela sabia que tinha uma clientela fiel. A TEAR tinha clientes que frequentaram a loja durante esses trinta anos e ainda traziam suas filhas e netas para consumirem seus produtos.

Foi então que Flora, uma das vendedoras mais antigas da TEAR, disse a Anna:

- Anna, querida, vamos fazer a terceira noiva da família Castro. Fizemos a avó, a mãe e agora a neta dela está aqui para conversar sobre o seu vestido.

Anna sabia que não poderia perder essa oportunidade e se aproximou para conversar com a noiva. Lara era uma menina jovem e alegre. Culta e extremamente viajada, Lara exibia seu anel de noivado e repetia várias vezes "o mais lindo de tudo foi vê-lo ajoelhado na Quinta Avenida com a caixinha azul nas mãos".

Anna logo percebeu que a garota se referia a Nova Iorque. "Uau”, pensou Anna. "Ela havia ficado noiva em Nova Iorque, mas escolheu comprar o seu vestido de casamento 
conosco". Anna apresentou-se a Lara e começou a ouvir a história do seu noivado. A jovem era apaixonada pela Tiffany por se tratar de uma empresa que desenvolvia suas joias por meio da valorização dos processos artesanais. Para ela, a Tiffany mostrou ao mundo como unir tradição, beleza e sofisticação em um produto artesanal.

- Ele realizou meu sonho de menina - disse Lara. "Sempre quis usar uma aliança Tiffany", completou.

Anna logo entendeu a razão de Lara estar ali. Aquela família sabia o valor da tradição artesanal, apesar da TEAR não conseguir transmitir isso da melhor forma possível. A jovem havia desejado um anel Tiffany, pelo mesmo motivo que desejou um vestido de noiva da TEAR. Após atender Lara e encaminharem todos os trâmites para a confecção do vestido, Anna não conseguia parar de pensar no motivo de Lara ter associado a TEAR à Tiffany. Será que era ali que ela encontraria sua inspiração para salvar a TEAR?

\subsection{UMA PRIMEIRA APROXIMAÇÃO COM A TIFFANY'S \& CO.}

Naquela noite Anna não dormiu, atracou-se com o seu notebook e seu tablet durante toda madrugada. Encantada com tudo que lia, ela passou a investigar sobre a Tiffany, loja de decoração de Charles Lewis Tiffany que chegou em Nova York em 1837 trazendo uma visão de beleza fora do comum e passou a redefinir o glamour e o estilo em todo o mundo. As leituras fizeram Anna perceber que ali poderia encontrar muitas respostas. Além de rever muitas curiosidades sobre como aquele pequeno negócio tinha se transformado em um ícone mundial, ela, enfim, tinha compreendido a força e o significado da "caixinha azul" citada por Lara. O azul Tiffany é tão especial e famoso que se tornou uma cor oficial do sistema Pantone. O sistema Pantone é baseado em uma mistura específica de pigmentos para se criar novas cores em um padrão mundial. Existia mesmo a cor “Azul Tiffany”.

O mito ultrapassa décadas e o site da Tiffany serve de instrumento para cultuá-lo. Lá, Anna encontrou uma área dedicada a explicar a importância das caixinhas azuis. Um patrimônio que, como eles dizem, não importa se "vislumbradas em uma movimentada rua ou seguradas na palma da mão, as "Tiffany Blue Boxes" fazem corações baterem mais forte e representam a grande herança da Tiffany em termos de elegância, exclusividade e arte manual impecável".

Anna também descobrira sobre as tradicionais alianças. Desde 1886, Charles Lewis Tiffany apresentou o célebre anel de noivado com diamante em Tiffany®. E este tem determinado o estilo e celebrado as grandes histórias de amor de todo o mundo. Ela achou até 
a imagem de um recorte do New York Sun datado de 1906, onde se podia ler "Tiffany tem algo em estoque que você não pode comprar, independentemente do dinheiro que possa oferecer; algo que poderá ser somente dado a você. E é uma de suas caixas”. Em meio a essas investigações sobre as tradicionais alianças, de repente, ela se viu diante de algo totalmente inesperado: um aplicativo da Tiffany.

- Como ela nunca tinha notado aquilo antes? - perguntou-se em voz alta.

O aplicativo da Tiffany permite que você projete a imagem dos anéis que deseja usar no seu noivado no dedo da futura noiva. Basta fotografar a mão, escolher o modelo e, se quiser, ainda permite compartilhar o "sim" em suas redes sociais. Mas, não era só isso. A Tiffany também tinha perfil em todas as redes sociais em que ela era cadastrada.

De fato, a Tiffany poderia servir como referência nas boas práticas sobre como o uso de tecnologias pode agregar o valor aos produtos artesanais e transformá-los em objetos de desejo.

Anna descobriu que a Tiffany publicara seu primeiro catálogo, conhecido por "Blue Book" em 1845. Primeiramente impresso e distribuído pelos correios, hoje disponível no site da loja em vários idiomas. Esta apresentação anual passou a reunir joias que demandavam uma habilidade manual impecável e design inigualável. Sua primeira edição lançou a temporada de outono com uma das maiores e mais requintadas coleções de joias refinadas do mundo. Até hoje, essas estonteantes obras-primas de gemas extremamente raras são ansiosamente esperadas pelos conhecedores de joias de todo o mundo, que vão até a Tiffany para serem os primeiros a ver e comprar esses tesouros únicos.

Eram tantas inovações ao longo da sua história, sempre unindo tradição, inovação e novas tecnologias, que deixaram Anna perplexa. Como era possível uma marca tão tradicional estar sempre tão bem sintonizada com as tendências mundiais de comportamento e de recursos tecnológicos?

Desde 2015, o vídeo da campanha publicitária “Will you?” já havia atingido mais de um milhão visualizações no canal oficial do Youtube da Tiffany \& Co. Nesta campanha, um casal gay aparece dentre os casais que estão fazendo promessas de amor. Ela leu que, em entrevista para CNN, a Tiffany declarou que dentre os modelos contratados, o casal gay era um casal real e que resolveram adotar esta postura, pois a Tiffany se dizia uma empresa que acredita no amor. O representante da Tiffany disse à revista Elle daquela época: "O amor verdadeiro pode acontecer mais de uma vez, em histórias que vêm nas mais variadas formas". Anna também leu sobre quando a Tiffany lançou um site mundial onde as pessoas que ficavam noivas com os anéis da Tiffany podiam contar suas histórias de amor. Depois surgiu 
o projeto "What makes love true" que mostrava as pequenas coisas que fazem o amor ser real.

Nos dias seguintes as pesquisas intensificaram-se e Anna descobriu que houve uma campanha da Tiffany que fez muito sucesso no Instagram, intitulada de "True Love in Pictures", onde casais reais compartilharam fotos de momentos do cotidiano que demonstravam o amor verdadeiro. Os dias foram passando e sempre havia uma nova postagem da Tiffany para provocar a curiosidade e imaginação de Anna. O Instagram era o seu preferido.

Quando chegou o momento de conversar do Nina, Anna a surpreendeu com a notícia de que precisava ir a Nova Iorque para finalizar sua proposta de recuperação da organização.

- Mãe, identifiquei algumas boas referências que poderão servir de inspiração para os nossos projetos futuros. Hoje, escrevi para Tiffany pedindo uma visita oficial à loja da Quinta Avenida. Assim que me responderem, partirei em viagem - disse Anna.

Alguns dias depois, o esperado e-mail chegou. Sr. Chan, gerente de mandarim, tinha disponibilidade na agenda, mas Anna teria que correr, pois o compromisso seria na semana seguinte.

\subsection{DO DIGITAL AO CORPORAL: VISITANDO A LOJA DA TIFFANY'S \& CO. EM NOVA IORQUE}

No dia 20 de dezembro, chegaram em Nova Iorque. Anna viajou com seu amigo Tony. Ela tinha planos para convidá-lo a trabalhar na TEAR. Tinham trabalho juntos em algumas das empresas por onde Anna passou ao longo de sua carreira. Anna sabia que precisaria de alguém antenado para ajudar a tocar este novo desafio e Tony tinha o perfil mais adequado para isso.

Deixaram as malas no hotel, no meio do furdunço de Natal e já correram para ver a cidade. Caminhando pelas ruas, Anna recorreu ao seu celular, baixou o aplicativo do metrô e seu guia da cidade. Em seguida, consulta logo seu bloco de notas e diz para Tony:

- A nossa primeira parada é essa aqui. Apontando para o seu celular, Anna mostra na tela: “727 5th Ave, New York, NY 10022, Estados Unidos”.

Ainda era cedo e como o inverno estava bastante rigoroso, o sol só chegava depois das 9 horas. Foi mais ou menos neste horário que os dois chegaram na porta da Tiffany's \& Co. pela primeira vez. Parecia mágica o brilho daquelas portas douradas com sua fachada decorada com luzes, guirlandas e bolinhas de Natal azul Tiffany.

Eles se entreolharam e Tony lhe estendeu o seu copo de café que tinha comprado 
quando saíram do hotel. Nesse instante, as portas se abriram. Tony e Anna terminaram o café e entraram naquele salão mágico. Ela estava lá, no famoso edifício de granito e calcário, todo em Art Déco e portas de aço inoxidável. No alto, a famosa escultura em bronze de dois metros e meio de Atlas carregando um relógio nos ombros. Dentro havia uma decoração de Natal impecável, tudo azul Tiffany. Vitrines deslumbrantes. Funcionários simpáticos e um gerente para cada idioma dos clientes que normalmente frequentavam a loja. Parecia que as vitrines eram acessíveis a todos, ao mesmo tempo que cada um dos itens exibidos parecia ser muito exclusivos.

- Tenho um horário agendado com o Sr. Chan, - disse Anna à recepcionista da loja.

De repente, um senhor oriental dirigiu-se até eles: Posso ajudá-los? Era a voz do Sr. Chan, o gerente de atendimento em Mandarim.

Tony contou ao Sr. Chan o quão importante era aquele momento. Juntos, visitaram os diferentes andares da loja. Seguiram para o elevador, a fim de contemplar um passeio que Anna já tinha feito pela Internet, através das fotos postadas nas redes sociais. Mas, agora, seria a primeira vez que viveria, em carne e osso, aquela experiência. Viram um andar para as joias mais valiosas, um andar para artigos de decoração e os famosos vidros e cristais, andares e mais andares. Até que pararam no andar das alianças. Assim como nos outros, desceram do elevador, observando atentamente como aqueles anéis eram expostos para despertar ainda mais o desejo das pessoas em possuí-los.

Diante do encantamento dos dois, Sr. Chan contou toda a tradição de lapidação das gemas e como o processo ainda era totalmente manufaturado.

- Percebem o cuidado em que as peças são expostas? - disse Anna para Tony.

Sr. Chan os convidou para se inscreveram na visita à Oficina Tiffany, onde seria possível ver os artesãos trabalhando na lapidação das pedras. Segundo o gerente, na visita era possível testemunhar todo o desenvolvimento de uma peça e assim reconhecer como é especial o processo artesanal. Anna sabia que a Tiffany tinha retratado este processo em uma das suas campanhas do Instagram, através de fotos que mostravam a construção de alguns anéis do início ao fim. Como se pensassem a mesma coisa ao mesmo tempo, Tony e ela se entreolharam:

- Poderíamos fazer o mesmo com as peças da TEAR.

Enquanto Sr. Chan conversava com eles, Anna avistou uma mulher muito emocionada, sozinha, ganhando um buquê de rosas vermelhas das mãos de uma vendedora. Anna apontou para a cena e perguntou:

- O que é aquilo Sr. Chan? Por que aquela senhora está ganhando um buquê da Tiffany? Deve 
ter feito uma compra importante! Os três assistiram à cena e viram a senhora se despedir da vendedora com sua sacolinha azul e seu buquê de rosas.

Sr. Chan percebeu que Anna queria mais informações sobre aquele momento. Foi então que ele explicou sobre a autonomia que alguns vendedores possuíam para tornar o momento Tiffany ainda mais especial. Para que pudessem entender ainda mais o que seria um momento especial, chamou a vendedora Marisa para que ela os explicasse o acontecido.

- Marisa, por que usamos o buquê especial com aquela senhora?

Marisa explicou que quando a senhora entrou na loja contou que tinha comprado sua primeira joia Tiffany há oito meses atrás, quando descobriu um câncer. Segundo a cliente, o pingente de coração azul fora seu amuleto da sorte durante toda a quimioterapia. Hoje, após sua última sessão, passou pela porta da loja e decidiu que precisava de um novo amuleto para seguir a vida, portanto, entrou e comprou um par de brincos.

- Fiquei tão comovida com a sua história que quis homenageá-la. A sua história traduz o que a Tiffany tanto prega em suas ações, ou seja, todo cliente e toda história é especial. Ainda mais neste caso, disse Marisa ao Sr. Chan, Tony e Anna.

- Quanta emoção para uma primeira visita à loja da Tiffany! - concluiu Anna.

Os três seguiram em visita e, ao final, Sr. Chan os surpreendeu conseguindo encaixálos no grupo que faria uma visita à oficina nos próximos dias. O começo da viagem estava incrível, "mas nem só de Tiffany vive Nova Iorque", disse Tony. Amantes das artes e de cultura, os amigos tinham organizado uma programação intensa para os próximos dias, precisavam explorar ao máximo aquela cidade de tradições e inovações.

\subsection{OUTRAS EXPERIÊNCIAS DIGITAIS E CULTURAIS EM NOVA IORQUE}

Naquele mesmo dia, Tony e Anna passearam na Time Square, visitaram algumas lojas, e, ao final da tarde, seguiram para o Top of The Rock e para a Christimas Tree para finalizarem o dia e assistirem ao pôr do sol em uma das vistas mais bonitas de Manhattan. $\mathrm{O}$ Top of the Rock é o píer do Rockfeller Center, prédio que hospeda a famosa árvore de Natal da cidade. Anna ficou encantada em como a história da árvore e do prédio eram contadas e como os ingressos eram vendidos. O acesso ao píer era uma experiência cultural vendida como um produto e tinha um suporte tecnológico incrível. Os ingressos eram comprados em totens conectados à Internet, onde se podia assistir ao vídeo de sua história através de um canal no Youtube. Em seguida, os visitantes eram direcionados à uma loja virtual onde se pagavam os tickets com cartão de créditos. Tudo com hora marcada para evitar filas nos 
elevadores e qualquer desconforto na experiência.

- Tony, não acha incrível como a tecnologia pode dar suporte a experiências tão tradicionais? Assim como a Tiffany, aqui o tradicional e o contemporâneo se une com perfeição e ainda faz as coisas parecerem mais interessantes e sofisticadas.

- Não tinha pensado dessa forma. Você tem razão. Temos tudo isso no Brasil, mas apresentamos nossos produtos tradicionais de forma tão óbvia que perdemos a chance de ganhar todo esse glamour e cobrarmos um valor mais justo por eles. Será que não é isso que está acontecendo com a TEAR? - Afirmou Anna.

O papo continuou enquanto subiam o elevador. De lá de cima, uma vista incrível finalizou a tarde. Encantados com tudo aquilo, no final do passeio, ao se dirigirem para o elevador para descerem de volta, sem esperar, percebem que o lobby do elevador hospedava uma lojinha de souvenir.

- Imagine, depois da mágica, ainda tem a lojinha, disse Tony. Estamos tão apaixonados que queremos comprar tudo. Será que é de propósito, Anna? Jamais compraria uma foto da obra que gerou a primeira árvore, mas agora que sei que a primeira árvore foi um presente para os operários, a foto fica linda!!!

- Tony, era exatamente sobre isso que falávamos no elevador de subida. Tudo é como apresentamos o produto, construímos seu valor simbólico e o experimentamos. Um produto comum pode ser apresentado como uma experiência cultural e assim o valor se cobra por ele ganha outro significado e outro valor.

Por fim, depois de um dia inteiro batendo perna, foram para hotel descansar. Doze horas de voo e tantas emoções o deixaram exaustos.

No dia seguinte foram visitar alguns museus. No museu 911, em homenagem às vítimas do atentando terrorista do onze de setembro, o qual foi construído no local do World Trade Center, também conhecido como Torres Gêmeas, a experiência foi bem facilitada. Os ingressos já tinham sido comprados pela Internet antes mesmo de saírem do Brasil. Para acessar o local, basta apresentar o código de acesso na própria tela do celular e a leitora permite a entrada. Apesar de um belo lugar, a experiência é bastante forte, duas piscinas ocupam o lugar das torres e não se pode ver o fundo deles. Em ambas, uma queda d'água contínua registra que as lágrimas dos americanos nunca irão secar por aquela tragédia.

Seguiram para o MET - Metropolitan Museum of Art. Anna já conhecia várias alas do museu. O MET tem seu próprio canal no Youtube, onde se pode assistir a história das obras. Como é apaixonada por museus, ela também os segue no Facebook, Pinterest, Twitter e Instagram. Apesar dos vídeos que já assistiu, Anna se emocionou em encontrar pessoalmente 
com as obras de artes, mas com certeza, poder vê-las também de longe motiva a visita.

No terceiro dia de viagem, resolveram ir ao Central Park e de lá caminharam até o American Museum of Natural History, o famoso Museu Americano de História Natural. Por uma feliz coincidência, dentro do museu se depararam com o Kwanzaa, um festival anual de cultura africana. Além de apresentações de teatro e dança, havia uma feira de produtos artesanais acontecendo no local. Anna aproveitou a oportunidade para conversar com alguns artesãos e entender como eles ofertavam, exibiam e vendiam os seus produtos.

No Kwanzaa, conheceu uma poetisa que exibia em seu tablet cenas dos seus esquetes para divulgação do seu trabalho. Neste tablet, seus potenciais clientes podiam consultar sua agenda e conhecer suas diferentes performances. Em outro stand, conheceu uma artista plástica que pintava quadros. Anna se interessou por uma de suas obras, mas teve dúvidas se ficaria bom se o colasse sobre o seu sofá da sala. Portanto, tentou explicar sua exitação para a artista, quando foi surpreendida com uma proposta:

- Me manda uma foto do seu apartamento pelo WhatsApp que aplico a imagem do quadro em proporções reais e te devolvo para ver o que acha, disse Eletria, a artista.

Anna explicou que era turista e que não tinha uma foto com tais característica. Então Eletria a surpreendeu mais uma vez:

- Entra no meu site, conhece meu trabalho e escolhe a obra que mais lhe agradar. Em seguida, acesse a loja virtual e faça o upload da foto da sua parede. Quando receber a mensagem com a imagem simulada, você decide se quer. Lá você pode colocar seu CEP e pagar com seu cartão de crédito internacional. Não se preocupe que vendo assim para o mundo todo.

Feliz com a desenvoltura daquela jovem artista, Anna se despediu bastante animada com a proposta e seguiu para o próximo estante, onde Tony já estava experimentando os adornos e chapéus de uma senhora do Harlem. Ella era artesã e fazia manualmente os seus adornos, juntamente com as demais senhoras do bairro do Harlem. Apesar de serem senhoras, o seu stand também contava com um bom suporte tecnológico. Era possível conhecer suas redes sociais e realizar o pagamento através de um aplicativo instalado no tablet. Quando pediram o seu cartão de visitas, ela me informou que chegaria por mensagem nos celulares após o cadastro.

Escolheram o que queriam, pagaram com cartões através de uma leitora acoplada ao tablet e receberam a nota fiscal por e-mail. Tudo online, mesmo em uma venda física.

Os dias em Nova Iorque continuavam incríveis, mas Anna esperava ansiosamente pelo dia da visita à Oficina da Tiffany.

Enfim, a sexta-feira chegou. 


\subsection{A VISITA NA OFICINA DA TIFFANY'S \& CO.}

As 9:30 da manhã já estavam lá. Rita, funcionária responsável pela visita à oficina os aguardava com crachás de acesso a essa área restrita. Anna e Tony iriam conhecer o que poucos clientes acessam. Ao começar o passeio ficaram logo chocadas com a primeira visão: dez artesãos trabalhavam numa sala cheia de câmeras de segurança com pedras de até 175 quilates sobre as mesas. Cada um com sua atribuição específica. Sr. José só fazia anéis, enquanto que o Sr. Benjamin cuidava da lapidação. Eles explicaram aos visitantes que um bracelete cravejado pode levar até 170 horas em desenvolvimento. "Um vestido de noiva também" - pensou Anna.

O tour também inclui uma parada no Tiffany Salon, local onde ficam as joias realmente importantes. As joias ficam expostas em vitrines embutidas na parede. Tudo muito elegante e sofisticado. Anna e Tony ficaram boquiabertos com icônica peça "Bird on the Rock", um desenho original do Jean Schlumberger que fora desenvolvida neste ateliê da Quinta Avenida. Anna havia lido sobre aquela peça. Em 1995, o Museu do Louvre recebeu a exposição "A Diamond in the City", que tratava de uma retrospectiva do trabalho de Jean Schlumberger.

-O arquiteto que projetou o espaço foi o Robert A. M. Stern, o mesmo que fez o apartamento mais caro de Nova York, vendido para russa Ekaterina Rybolovleva por U\$ 88 milhões disse Rita.

Anna estava impressionada com as coisas que ouvia e via. Que experiência fantástica! Foi possível ver todo o processo de lapidação e confecção das joias permaneciam muito artesanal. Fica claro como a tradição está amparada em tecnologias de processo, mas também como o trabalho artesanal garante a integridade das peças Tiffany. Ao final do passeio, foram conduzidos para mais uma visita à loja com algumas sugestões de compras, seguindo a descrição dos andares onde podiam encontrá-las.

- Como é interessante primeiro visualizar o processo para depois seguir para as compras! Apesar de não poder pagar por muitas das peças que estão expostas aqui, não consigo achar nada caro ou de valor injusto, disse Anna.

A visita à Oficina gerou um impulso de compra forte e Anna decidiu que também compraria alguma joia da Tiffany antes de retornar para o Brasil.

- Quero uma pulseira com o berloque "Return to Tiffany" - disse Anna.

Tony comentou em seguida:

- Você merece uma joia Tiffany. Os anéis de noivado são sim uma tradição da marca. Lembro 
bem quando me contou que a Tiffany foi para a China e, ao perceber que não existia a tradição do anel de noivado no país, primeiro focou em realizar ações para divulgar esta tradição e, só depois, desenvolveu uma campanha com as suas alianças. Isso é que é crença nos seus produtos.

Anna sabia que Tony estava certo. Portanto, olhou ao seu redor e escolheu uma pulseira com o pingente de coração "Return to Tiffany". De uma lado a frase, do doutro o azul Tiffany. Embalados de forma precisa, como sempre sonhou, caixinha, sacola e laço.

- Agora sim, hora de voltarmos para tentar ajudar a TEAR no seu novo futuro.

\subsection{UMA PROPOSTA COM BASE NO VALOR SIMBÓLICO, NA CULTURA E DO MARKETING DIGITAL}

De volta ao trabalho, Anna sentiu que, de fato, poderia contribuir com um novo futuro para TEAR. Através da experiência com a Tiffany e sua viagem à Nova Iorque, a jovem gestora percebeu algumas formas para conciliar tradições artesanais com tecnologias para trazer visibilidade para o negócio. Seria preciso manter a identidade da empresa e a tradição dos fazeres artesanais tão bem defendidos e valorizados pela sua mãe e, ao mesmo, contextualizá-los de forma mais contemporâneo com o mercado.

Uma semana depois, a proposta estava pronta. Anna precisa fazer uma análise bem detalhada para transmitir tudo que viveu à sua mãe e ao mesmo tempo, propor as adaptações necessárias para o seu tipo de negócio.

\section{NOTAS DE ENSINO}

No campo da Administração, a criação de valor simbólico atribuído a bens de consumo tem se tornado um aspecto importante das práticas de gestão. Essa criação preocupase com a significação cultural de produtos e serviços, bem como com seus reflexos para as práticas de gestão. Há pesquisas que enfocam esses aspectos, mas poucas consideram as questões ligadas ao contexto digital da criação de valor simbólico. Esse caso permite integrar essas duas dimensões.

No campo do Marketing Digital, as pesquisas abordam todos os instrumentos e processos de comunicação e comércio por meio da Internet, todavia, poucos são os que consideram os aspectos culturais e simbólicos como sendo determinantes. Este caso permite integrar a dimensão cultural e simbólico à dimensão mais instrumental e técnica das teorias de 
marketing digital.

A conciliação entre cultura, simbolismo e marketing digital é discutida por meio, sobretudo, do caso da Tiffany \& Co, que, com seu legado de joias e lapidações de pedras e diamantes, tornou-se um dos grandes ícones mundiais da indústria do luxo, devido a sua incontestável capacidade de unir tradição, identidade e fazeres artesanais à comunicação e gestão de marca. Apesar de uma imagem extremamente tradicional e de grande valor agregado, a partir dos aspectos de intangibilidade de seus produtos, a Tiffany também se tornou referência em práticas de Marketing Digital. Presente nas grandes redes sociais, a Tiffany fortalece seus vínculos com seus públicos e legitima a sua identidade cultural, através dos seus posts, tweets e sites, oficialmente, traduzidos em cerca de 10 idiomas. A organização também possui dois aplicativos de celular, em versão para Android e aparelhos Apple, um deles com recursos tecnológicos de última geração que simula para o cliente a possibilidade de experimentar os tradicionais anéis de noivados da Tiffany. Em alguns países, a Joalheria possui lojas virtuais, com toda estrutura para escolha das joias e pagamento online dos produtos.

\subsection{ENSINANDO SOBRE O SIGNIFICADO CULTURAL E VALOR SIMBÓLICO DOS BENS DE CONSUMOS NA ERA DIGITAL}

\subsubsection{Objetivo educacional e referências para orientar a análise}

Dentro da aprendizagem de conteúdos da Administração, as disciplinas voltadas para cultura, identidade e simbolismo podem utilizar este caso para favorecer o entendimento de como os significados culturais e o valor simbólico são criados pelas organizações e integrados em suas estratégias digitais de comunicação com seus consumidores.

O valor simbólico de um produto pode ser compreendido pelos elementos intangíveis que o integram. Para compreensão sobre o universo dos produtos culturais, valor simbólico e a relação entre cultura e bens de consumo, sugere-se as leituras dos artigos de Ravasi e Rindova (2013) e de McCracken (2007) que integram as referências deste caso.

A fim de complementar esta abordagem, o filme "Walter Longo e os Desafios do Marketing e da Comunicação na Era Pós-Digital”, disponível em <https://www.youtube.com/embed/5WzaJ8DYFIM >, contribui para melhor contextualizar o processo de aprendizagem. 


\subsubsection{Estratégia Pedagógica}

$\mathrm{Na}$ aula anterior à aplicação deste caso de ensino, orienta-se que os estudantes realizem uma leitura prévia dos textos. É importante que tenham uma fundamentação prévia sobre o universo dos produtos culturais, seu caráter simbólico e como as tradições artesanais se inserem neste cenário. Pode-se, também, explicar definições de produtos culturais, enfocando aqueles produtos que envolvem tecnologias de produção enredadas de tradições locais artesanais, expressas em diferentes formas, sejam têxteis, em madeira, cerâmica, vidro, metal e outros. Produtos culturais incluem, ainda, aquilo que pode ser tipicamente chamado de artesanato, ou até os produtos que têm uma maior participação das mãos do que das máquinas. Neste caso, pode-se chamar também de produtos culturais utensílios domésticos decorativos, como jarros, porta-retratos, caixas, mesas, vasos e tapetes, bem como vestuário, joias e até brinquedos, desde que possuam os requisitos anteriormente citados (LITTRELL; MILLER, 2001, p.67-86).

Comece a realização da atividade com a enunciação do objetivo, a situação de desempenho de papel (os estudantes irão desempenhar o papel de Anna) e com as questões de análise. Depois, convide os estudantes a realizar a leitura do caso de ensino. Em seguida, exiba o filme "Walter Longo e os Desafios do Marketing e da Comunicação na Era PósDigital".

É importante destacar que as questões norteadoras não buscam tratar e/ou gerar uma discussão sobre o porquê da Web ter evoluído da sua versão 1.0 para 2.0 para 3.0, mas sim de como os administradores precisam se preparar para os desafios de gestão e da comunicação inerentes a sua atuação no contexto atual.

Os estudantes são convidados a desempenhar o papel de Anna e devem realizar o projeto para apresentar a diretora da TEAR. Algumas questões norteadores podem ajudar os estudantes a elaborarem esse projeto:

- Questão \#1

Como podemos caracterizar e descrever os produtos Tiffany em relação aos significados culturais e valor simbólico que lhe são atribuídos? Quais estratégias foram utilizadas pela organização para favorecer essa criação de significados e valores?

- Questão \#2

O que podemos aprender com as outras experiências vivenciadas por Tony e Anna em Nova Iorque em relação ao consumo produtos culturais que representam a "transferência do mundo para o bem de consumo"? Por quê? 


\section{- Questão \#3}

Como a TEAR poderia melhorar a criação de significado cultural e valor simbólico de seus produtos e serviços com base nas experiências nova iorquinas?

\subsubsection{Análise do Caso}

- Análise da Questão \#1

A caracterização dos produtos da Tiffany não deverá elencar apenas os aspectos de luxo e sofisticação dos produtos. É importante destacar a tradição que envolve o saber e o fazer de todas as joias e demais artefatos confeccionados pela organização. Isso envolve a experiência da oficina, onde o cliente compreende o processo artesanal como o elemento que garante a exclusividade e a sofisticação dos produtos.

Neste sentido, McCracken (2007, p. 101) nos lembra que "os bens de consumo têm uma significância que vai além de seu caráter utilitário e seu valor comercial”. Destaque os trechos do caso que demonstram os valores simbólicos expressos nos produtos Tiffany’s e as estratégias utilizadas para disseminação da sua cultura. Pode-se utilizar como exemplo, a passagem que demonstra a descoberta de Anna sobre o universo Tiffany e a sua história, bem como a experiência de visita à loja e ao ateliê dos artesãos.

Leve em consideração que "os princípios culturais são as premissas básicas que permitem que todos os fenômenos culturais sejam distintos, classificados e inter-relacionados. (MCCRAKEN, 2007, p. 103) Além disso, sabemos que o valor simbólico de um produto é determinado pelos significados sociais e culturais a ele associados, os quais permitem aos consumidores expressarem a identidade individual e social por meio da compra e uso do produto (RAVASI, RINDOVA, 2013, p.14).

Lembre-se que, no debate, deve-se estimular o estudante a entender como é possível expressar a intangibilidade dos produtos e como se torna um diferencial competitivo o cuidado ao trabalhar a identidade organizacional associado à tradição e ao artesanal como elemento central.

- Análise da Questão \#2

Para tal solução, deve-se destacar cada uma das experiências vivenciadas por Anna e Tony e como elas expressam o valor simbólico e os elementos culturais que ressignificam cada experiência. Os destaques estão por conta da Christimas Tree, Top of The Rock e os museus visitados. Neste momento há a oportunidade de associar às diferentes formas como isso está expresso, seja através de um site, um ingresso, um canal no Youtube ou a 
ambientação do local de consumo.

Para uma melhor compreensão sobre o universo desta questão, sugere-se um enfoque no trecho do artigo de McCraken (2007, p.101-105) onde se destacam os instrumentos de transferência de significados. Os rituais apresentados na leitura estão implícitos no contexto das experiências vivenciados por Anna e Tony.

Indique também a leitura do texto do artigo de McCraken (2007, p. 108-110) onde aparecem os instrumentos de transferência de significados: do mundo para o bem de consumo. Com esta leitura será possível evidenciar as estratégias utilizadas pela organização para transferência do significado do mundo culturalmente constituído para residir nos bens de consumo.

Ravasi e Rindova (2013, p. 17) apontam ainda para a crescente tendência que as empresas estão adotando para envolver os clientes ao longo da dimensão simbólica da troca. Eles estariam apelando para que estes desenvolvam uma compreensão mais profunda dos processos de construção de significados dos mercados. Estes processos poderão ser exemplificados a partir da descrição das experiências vivenciadas pelos personagens, em especial as experiências vivenciadas no Top of The Rock, Empire State e museus visitados pela dupla.

Para encerrar, desperte a atenção dos estudantes para um debate que aponte as dimensões funcionais e simbólicas, baseando-se na Tabela 2.6.1 oriunda do artigo de Ravasi e Rindova (2013, p. 20), onde se encontra a análise do lado funcional em relação com o lado simbólico dos produtos.

- Análise da Questão \#3

Neste item, deve-se descrever os aspectos de cultura e o valor simbólico expresso nas peças comercializadas pela TEAR. Deve-se destacar os saberes e fazeres que estão inseridos na sua produção e como estes representam elementos da cultura brasileira. É importante que o estudante perceba que a TEAR não comercializa apenas peças de roupas.

A fim de promover uma abordagem mais prática neste questionamento, proponha uma maior discussão sobre a Figura 2.6.1 do artigo de Rindova e Ravasi (2013, p.20). Para cada um dos elementos da ilustração deve-se buscar associá-lo aos itens que seriam correspondentes à realidade vivenciada pela TEAR. Por exemplo, deve-se provocar os estudantes a entenderem quais seriam as "culturas líderes e expressões culturais" que integrariam o esquema da TEAR, ou seja, elencar os saberes e fazeres que estão expressas em suas roupas.

No outro extremo da ilustração, têm-se o elemento "cultura de consumo em 
geral/padrões de uso e de expressão". Neste momento, deve-se associar as tendências de consumo de vestuário, baseado no perfil de consumidores da empresa.

Diante destes dois elementos centrais da discussão, deve-se conduzir o preenchimento dos demais elementos, demonstrando o que deverá constituir a produção do valor simbólico da TEAR, a partir da descrição dos envolvidos e dos processos pertinentes à própria rotina da organização.

Os demais elementos do esquema estão pautados nos conteúdos do artigo de Rindova e Ravasi (2013), em especial da página 21 até a 28.

\subsection{ENSINANDO SOBRE A RELEVÂNCIA DO SIGNIFICADO CULTURAL E DO VALOR SIMBÓLICO DE BENS DE CONSUMO PARA AS PRÁTICAS DE MARKETING DIGITAL}

\subsubsection{Objetivo Educacional e Referências para Orientar a Análise}

No que se refere aos conteúdos do Marketing, este caso pode ser utilizado para estimular a compreensão da importância dos significados culturais e do valor simbólicos para a realização de práticas de marketing digital.

$\mathrm{O}$ marketing digital surge como uma conceituação do marketing aplicada às possibilidades advindas do ambiente digital. Para uma melhor compreensão sobre este universo e o contexto de sua aplicação, sugere-se as leituras dos capítulos 4 ("Marketing digital", p.103-120) e 11 ("Presença digital”, p.249-260) do livro "Marketing na Era Digital" de Gabriel (2010). No capítulo 4, Gabriel (2010) busca apresentar diversas plataformas que podem ser usadas em conjunto com as plataformas já conhecidas, também chamadas de plataformas tradicionais. No capítulo 11, a autora direciona o conteúdo para a discussão sobre a presença on-line, o que aproxima o tema do marketing digital ao universo do valor simbólico e do significado cultural dos bens.

A entrevista de Martha Gabriel para a HSM intitulada "Como as Pequenas e Médias Empresas Podem Usar o Marketing Digital” (2012), disponível em $<$ https://www.youtube.com/watch? $\mathrm{v}=\mathrm{wxB} 5 \mathrm{~h} 7 \mathrm{Gh} 8 \mathrm{wg}\rangle$, contribui para a compreensão das mencionadas possibilidades de aplicação adaptadas às realidades das pequenas e médias empresas, como no caso da TEAR.

\subsubsection{Estratégia Pedagógica}


$\mathrm{Na}$ aula anterior à aplicação deste caso de ensino, orienta-se que os estudantes realizem uma leitura prévia dos textos. É importante que tenham uma fundamentação sobre o universo dos produtos culturais, seu caráter simbólico e como as tradições artesanais se inserem neste cenário. Pode-se, também, explicar definições de produtos culturais, enfocando aqueles produtos que envolvem tecnologias de produção enredadas de tradições locais artesanais, expressas em diferentes formas, sejam têxteis, em madeira, cerâmica, vidro, metal e outros. Produtos culturais incluem, ainda, aquilo que pode ser tipicamente chamado de artesanato, ou até os produtos que têm uma maior participação das mãos do que das máquinas. Neste caso, pode-se chamar também de produtos culturais utensílios domésticos decorativos, como jarros, porta-retratos, caixas, mesas, vasos e tapetes, bem como vestuário, joias e até brinquedos, desde que possuam os requisitos anteriormente citados (LITTRELL; MILLER, 2001, p.67-86).

Comece a atividade com a enunciação do objetivo, a situação de desempenho de papel (os estudantes irão desempenhar o papel de Anna) e com as questões de análise. Depois, convide os estudantes a realizar a leitura do caso de ensino. Em seguida, exiba a entrevista “Como as Pequenas e Médias Empresas Podem Usar o Marketing Digital”, disponível em $<$ https://www.youtube.com/watch?v=wxB5h7Gh8wg >.

A atividade pode ser realizada em equipes de quatro estudantes. Os estudantes vão desempenhar o papel de Anna e devem realizar o projeto para apresentar a diretora da TEAR. O projeto será orientado para um plano de marketing digital e comércio eletrônico que considere plenamente a questão dos significados culturais e do valor simbólico. Algumas questões norteadoras podem ajudar os estudantes a elaborar esse projeto

- Questão \#1

Como podemos caracterizar e descrever os produtos Tiffany, e das outras experiências novaiorquinas, em relação aos significados culturais e valor simbólico que lhe são atribuídos? Que estratégias foram utilizadas por cada organização para favorecer essa criação de significados e valores?

- Questão \#2

Descreva quais atividades de marketing digital seriam importantes para a TEAR e explique como seria possível integrar os significados cultural e o valor simbólico da organização nessas atividades.

- Questão \#3

Elabore três ações de presença on-line e marketing digital para propor para a TEAR. 


\subsubsection{Análise do Caso}

\section{- Análise da Questão \#1}

É preciso ficar claro para os estudantes que os elementos culturais e o valor simbólico dos produtos da TEAR é que nortearão as ações de marketing digital e não o contrário. Toda organização precisa ser fiel à sua identidade organização para conquistar a imagem desejada no mercado. Martha Gabriel (2010, p.105) destaca que "a proliferação de tecnologias e plataformas digitais oferece um cenário fértil para as mais diversificadas ações de marketing”. Portanto, o conteúdo é o que se destaca e não o simples uso dessas estratégias.

No contexto brasileiro, muitos negócios que envolvem produtos artesanais não percebem a relação direta entre a sua identidade cultural e o que ele produz. Por consequência, seu produto, apesar de expressar sua tradição e depender de um fazer artesanal, não consegue transmitir este valor simbólico. Para que haja valorização sobre o produto artesanal, é preciso considerá-lo quando produto cultural em todas as dimensões que o integra. Neste sentido, espera-se que os estudantes sejam capazes de compreender o diferencial competitivo desses produtos dentro das dimensões do seu caráter cultural e do valor simbólico que ele expressa.

No capítulo 11, Gabriel (2010, p.250) desperta para o fato de que as empresas precisam se perceber presentes digitalmente antes de empreender esforços em ações de marketing digital. "A presença digital, da mesma forma que a empresa/marca deve estar totalmente alinhada com o posicionamento da marca/produto e oferecer a melhor relação possível entre a experiência para o público e o retorno para a marca" (GABRIEL, 2010, p.250).

Neste sentido, deve-se destacar as percepções sobre o valor simbólico dos produtos Tiffany e a forma com que estes são expressos no mundo físico e no mundo virtual. Deve-se buscar elencar a relação direta entre ações que a empresa realiza, a exemplo da experiência vivenciada na oficina dos artesões e a experiência de poder visitar o catálogo "Blue Book", eletronicamente.

Outra comparação possível são as experiências vivenciadas nos museus, através do tour virtuais e a emoção vivenciadas pelos personagens na visitação física. Sobre as demais experiências, é importante que o estudante seja capaz de identificar as formas de aquisição dos bilhetes de acesso, os sites, o uso das redes sociais e demais experiências de consumo vivenciadas pelas plataformas digitais das empresas visitas e dos artistas do Harlem.

Para finalizar, proponha a construção de um quadro onde se identifique a estratégia 
virtual, a experiência física e a relação impressa do valor simbólico descrito nas duas propostas, bem como sua correlação. O Quadro 1 fornece um exemplo para estruturar a proposição:

Quadro 1 - Sugestão de quadro comparativo para análise do caso

\begin{tabular}{|l|l|l|}
\hline Experiência in loco & Experiência virtual & $\begin{array}{c}\text { Qual o valor simbólico expresso } \\
\text { em ambas experiências? }\end{array}$ \\
\hline & & \\
\hline & & \\
\hline & & \\
\hline
\end{tabular}

- Análise da Questão \#2

Para criar presença, as organizações contemporâneas utilizam-se de ferramentas e estratégias que vão desde a constituição de espaços virtuais de interação, públicos e privados, até plataformas que auxilia na construção de novos espaços de interação, bem como espaços de comercialização.

Nesse sentido, a gestão da comunicação digital, através das estratégias de marketing digital e comércio eletrônico, tem apoiado as organizações a vivenciarem o mundo virtual, ampliando as suas possibilidades de atuação. Como principais consequências, temos o aumento dos mercados consumidores e o avanço da visibilidade sobre determinados negócios. As ferramentas da Web, em sua maioria, são de fácil acesso e com custos iniciais iguais a zero ou próximo a isso. Uma melhor compreensão sobre a sua aplicabilidade pode contribuir para conquista de resultados satisfatórios.

Como diria Longo (2016), hoje só notamos o digital quando falta. O autor também destaca que "não é mais uma questão de utilizar as ferramentas ou 'armas digitais', e sim possuir uma alma digital”. Martha Gabriel (2010, p. 205) destaca que "a proliferação de tecnologias e plataformas digitais oferece um cenário fértil para as mais diversificadas ações de marketing”. Portanto, para atender às provocações da questão \#2, o estudante precisa indicar os valores organizacionais e como estes são transferidos para os bens de consumo comercializados pela TEAR.

No que tange as propostas de trabalho, as mesmas devem permear o uso das principais 
plataformas e tecnologias digitais como páginas digitais (sites, minisites, hotsites, portais, $b \log s$ ), além de perfis em redes sociais. Em sua lista, também pode ser considerado o uso emails como estratégias de comunicação e relacionamento, realidades mistas, tecnologias mobile, redes sociais, plataformas de buscas, games, canais e TVs digitais, dentre outras tecnologias.

As ações identificadas pelos grupos de trabalhos devem contemplar as categorias identificadas na Figura 1.

Figura 1 - Plataformas e tecnologias digitais de marketing

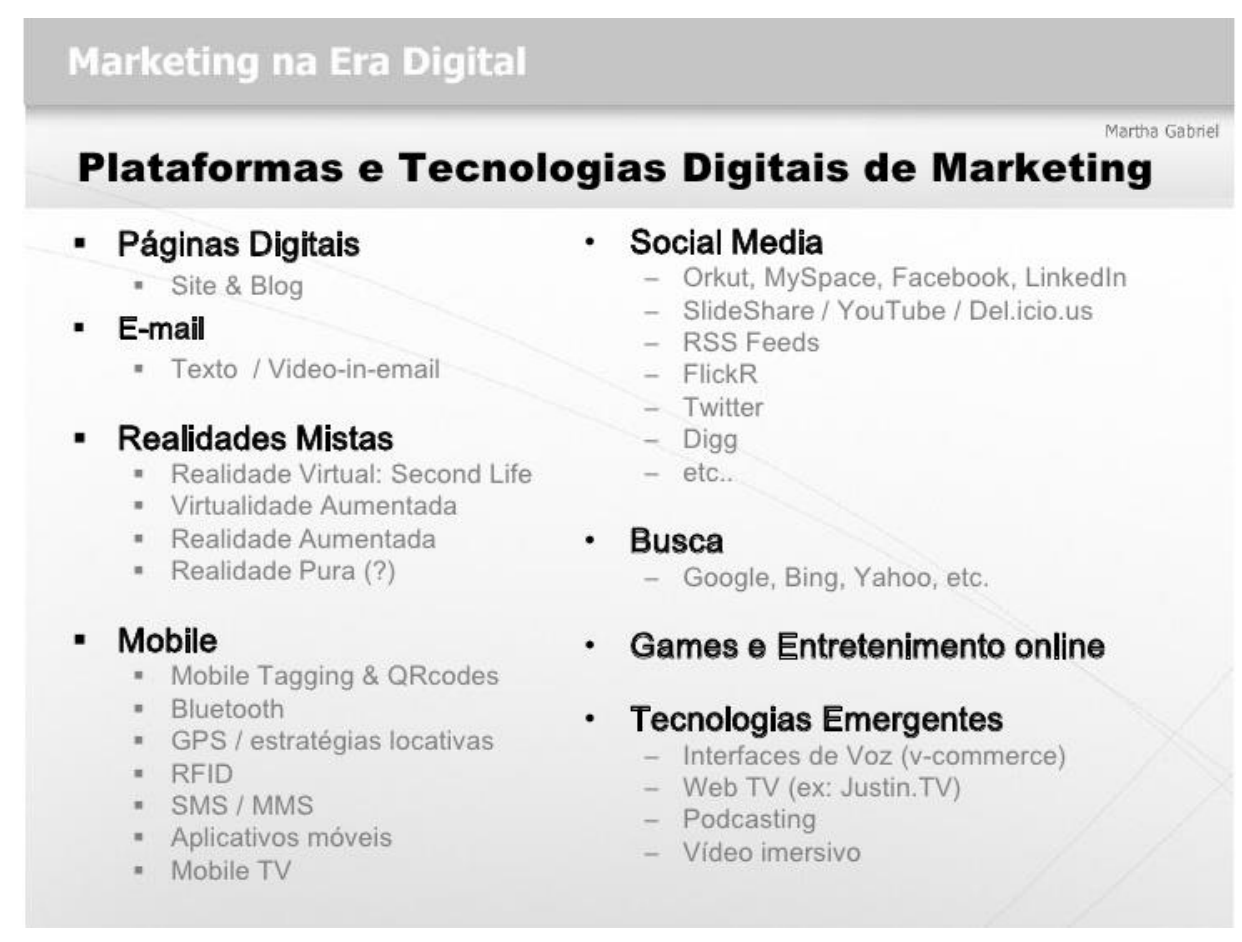

Fonte: Gabriel (2010, p.108).

- Análise da Questão \#3

Inicie esta discussão promovendo a retomada do debate sobre a presença no mundo físico e no mundo virtual. Neste sentido, Gabriel (2010) pode pautar a discussão diante da sua observação sobre o fato de ser interessante observar que é preciso ter uma presença on-line adequada antes de atuar no ambiente digital. Para a autora, a organização precisa identificar qual presença possui ou deseja possuir, ou seja, presença digital própria, presença gratuita ou ganha e presença paga. "Não ter presença digital significa não existir no mundo digital, na Internet" (GABRIEL, 2010, p.249). 
Diante da posição tomada pelo a organização, caberá, portanto, optar pelo tipo de presença bem como escolher dentre as possibilidades de presença que são apresentadas na página 251. É importante destacar que a TEAR está passando por uma crise financeira, bem como também está iniciando o processo de construção da sua presença digital. Portanto, os estudantes devem prioritariamente apontar para o uso de estratégia que mesclem estratégias próprias, gratuitas e pagas. Destaca-se ainda que a maior parte das estratégias pagas propostas pela autora poderiam integrar planos futuros, pois demandam um maior amadurecimento da presença digital antes do seu uso.

Além de analisar a proposição das ações, é importante que haja uma justificativa para cada uma delas. Neste sentido, oriente os estudantes a compreender o universo da estratégia proposta e os impactos que elas poderiam trazer para a o reconhecimento da TEAR. Não se deve esquecer que os elementos de cultura são os diferenciais competitivos da organização. Este deve ser o tema central das estratégias propostas.

No que tange às proposições das ações de marketing digital, as proposições valem-se das mesmas orientações. No entanto, a classificação deve seguir os conteúdos abordados na questão \#2.

\section{REFERÊNCIAS}

BARBOSA, L.; CAMPBEL, C. (Eds.). Cultura, consumo e identidade. Rio de Janeiro: Editora da FGV, 2006.

CAPOTE, T. Bonequinha de luxo. São Paulo: Companhia das Letras, 2005.

CASTELLS, M. A galáxia da internet: reflexões sobre a internet, os negócios e a sociedade. Rio de Janeiro: Jorge Zahar, 2003.

DAVEL, E.; CAVEDON, N. R.; FISCHER, T. A vitalidade artesanal da gestão contemporânea. Revista Interdisciplinar de Gestão Social, v. 1, n. 3, p. 13-21, 2013. DOUGLAS, M.; ISHERWOOD, B. O mundo dos bens: para uma antropologia do consumo. Rio de Janeiro: Editora da UFRJ, 2013.

ETSY. Compre diretamente de pessoas ao redor do mundo. Disponível em: <https://www.etsy.com/>. Acesso em: 6 Fev. 2016.

GABRIEL, M. Os Desafios para o marketing digital para 2015. Entrevista concedida para DigaAí TV. Disponível em: 〈https://www.youtube.com/watch?v=jGJ4oz6ppxg>. Acesso em: Acesso em: 6 fev. 2015.

GABRIEL, M., Entrevista com Martha Gabriel: como as pequenas e médias empresas 
podem usar o marketing digital. Disponível em

<https://www.youtube.com/watch?v=wxB5h7Gh8wg >. Acesso em: 6 fev. 2016.

GABRIEL, M. Marketing na era digital: conceitos, plataformas e estratégias. São Paulo:

Novatec, 2010.

GLAMOUR, Revista Blog. Bonjour, glamour! um café nos bastidores da tiffany.

Disponível em: < http://revistaglamour.globo.com/Moda/noticia/2012/06/cafe-da-manha-nosbastidores-da-tifdany.html> Acesso em 12 fev. 2016.

LITTRELL, M. A.; MILLER, N. J. Marketing across cultures: consumer's perception of product complexity, familiarity, and compatibility. Journal of Global Marketing, Vol.15, p.67-86, 2001.

LONGO, W. .Desafios do Marketing e da Comunicação na Era Pós-Digital. Entrevista concedida para Grandes Nomes da Propaganda. Disponível em

<https://www.youtube.com/embed/5WzaJ8DYFlM>. Acesso em: 6 fev. 2016.

LONGO, W. Marketing e comunicação na era pós-digital: as regras mudaram. São Paulo: HSM do Brasil, 2014.

MCCRACKEN, G. Cultura e consumo: novas abordagens ao caráter simbólico dos bens e das atividades de consumo. Rio de Janeiro: MAUAD, 2003.

MCCRACKEN, G. Cultura e consumo: uma explicação teórica da estrutura e do movimento do significado cultural dos bens de consumo. Revista de Administração de Empresas, v. 47, n. 1, p .99-115, 2007.

RAVASI, D.; RINDOVA, V. Criação de valor simbólico. Revista Interdisciplinar de Gestão Social, vol.2, n.2, p.13-35, 2013.

RAVASI, D.; RINDOVA, V.; DALPIAZ, E. the cultural side of value creation. Strategic Organization, v. 10, n. 3, p. 231-239, 2012.

SEMENICK, R. J.; BAMOSSY, G. Princípios de marketing em uma perspectiva global. São Paulo: Makron Books, 1996.

SENNETT, R. O Artifice. Rio de Janeiro: Record, 2009.

STRAUSS, J.; FROST, R. E-Marketing. São Paulo: Pearson Prentice Hall, 2012.

TURBAN, E.; KING, D. comércio eletrônico: estratégias e gestão. São Paulo: Prentice Hall, 2004.

TURCHI, S. R. Como começar a trabalhar com marketing digital. Disponível em:

<https://www.youtube.com/watch?v=8t2GkAUiqi8> Acesso em: 6 fev. 2016.

TURCHI, S. R. estratégias de marketing digital e e-commerce. São Paulo: Editora Atlas, 2012. 
TURCHI, S. R. O empreededorismo digital. Disponível em:

〈https://www.youtube.com/watch?v=-fdEnSMZ4HY>. Acesso em: 5 fev. 2016. 